\title{
Herbivory effects on leaf litter decomposition vary with special leaf area in temperate mixed deciduous forest
}

\author{
Yanchun Liu ${ }^{1}$, Xiaojing Liu ${ }^{2}$, Guoyong $\mathrm{Li}^{1}$, Zhongling Yang ${ }^{1}$, and Shirong $\mathrm{Liu}^{3}$ \\ ${ }^{1}$ Henan University \\ ${ }^{2}$ Baotianman Natural Reserve Administration \\ ${ }^{3}$ Chinese Academy of Forestry
}

May 12, 2020

\begin{abstract}
Insect herbivore has great impacts on biogeochemical cycling in forest ecosystem, but experimental tests on the herbivorydecomposability relationship at the inter-specific level are rare. We conducted a 400-day field decomposition experiment in a temperate mixed deciduous forest and measured mass remaining rate, decomposition constant, total loss of carbon (C) and nitrogen $(\mathrm{N})$ of litter leaf with/without obvious damage by chewing insects for different tree species. We found that herbivory effect on initial litter quality (C: $\mathrm{N}$ ratio) varied with species, showing a markedly negative effect on $\mathrm{M}$. alba (-5.78\%) and positive effect on Q. acutissima $(+5.35 \%)$. Herbivory damage increased decomposition constant for M. alba and L. formosana with higher special leaf area, but decreased it for D. kaki and Q. acutissima with lower special leaf area. The contrasting effects of insect herbivory on litter decomposition could be attributed to the variability of litter initial quality caused by herbivory. Our finding that herbivore damage showed inter-specific variability in both litter quality and decomposition rate suggests that herbivory induced feedbacks to nutrient cycling and ecosystem function should be estimated at the species level in multi-species mixed deciduous forest.
\end{abstract}

\section{Hosted file}

Paper-Ldd.pdf available at https://authorea.com/users/321230/articles/450495-herbivoryeffects-on-leaf-litter-decomposition-vary-with-special-leaf-area-in-temperate-mixeddeciduous-forest 

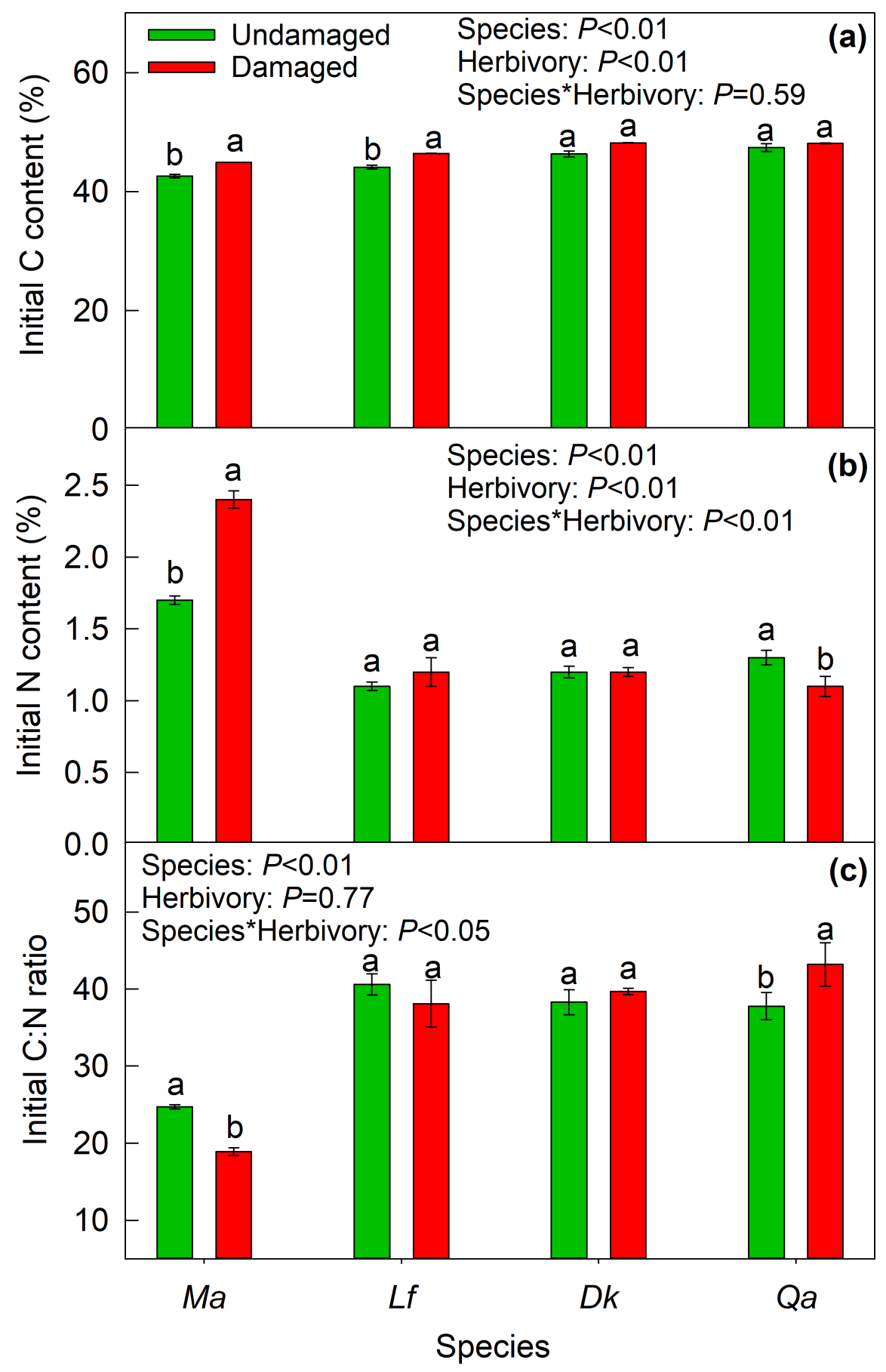


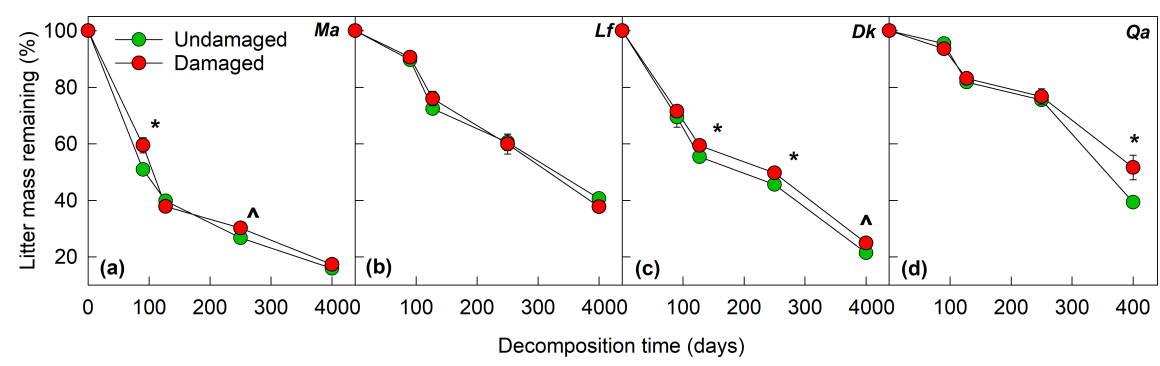




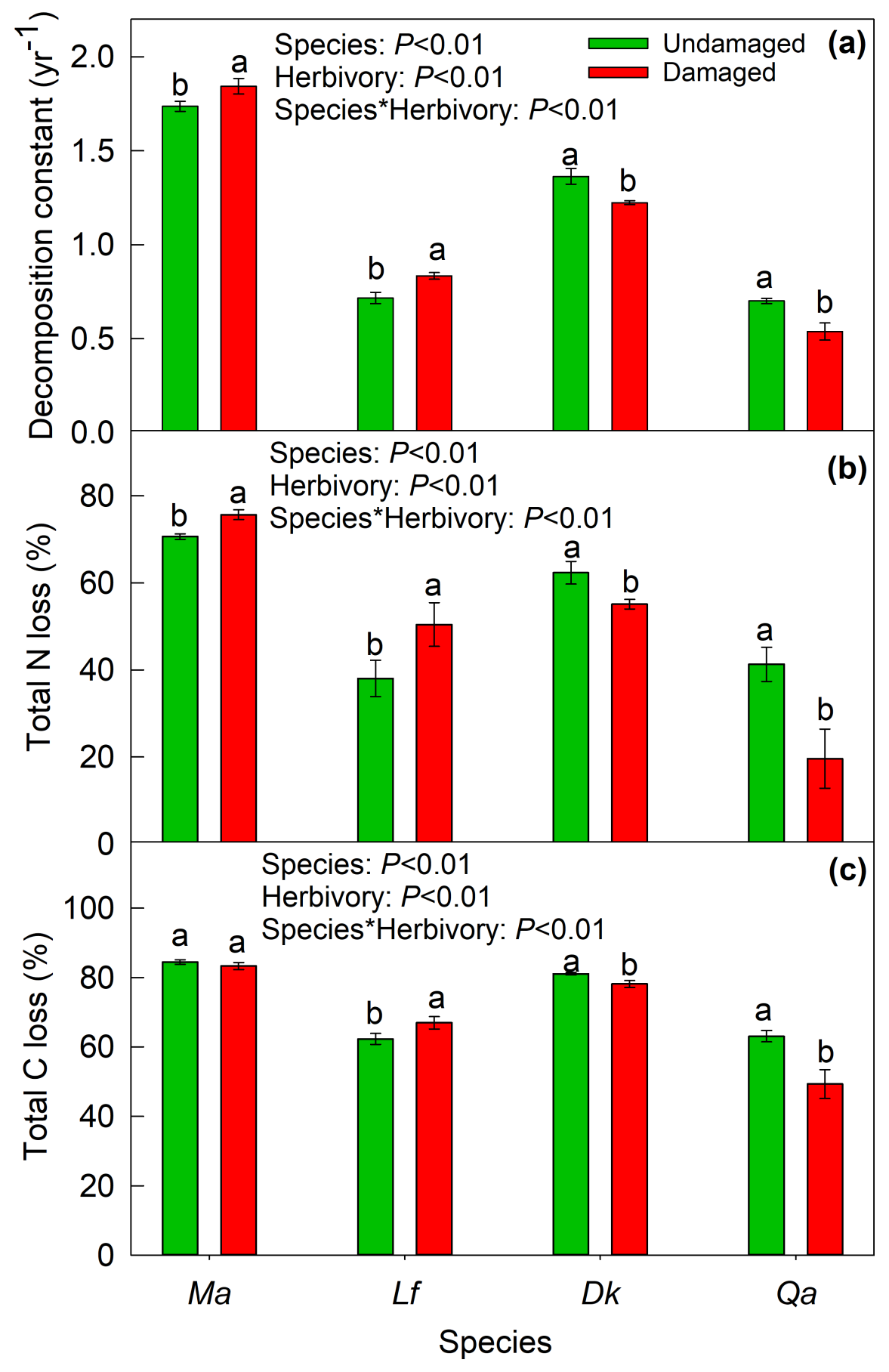




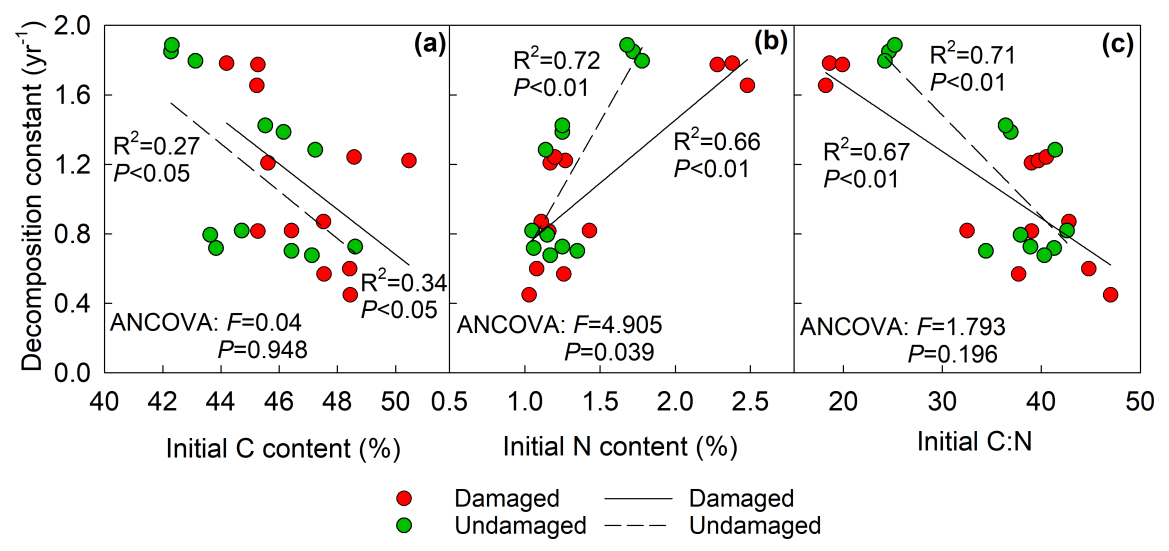

